\title{
Allowing for detachment processes in market innovation. The case of short food supply chains
}

\author{
Ronan Le Velly, ${ }^{\text {a }}$ Frédéric Goulet, ${ }^{\text {a, b, c }}$, \& Dominique Vinck ${ }^{\mathrm{d}}$
}

${ }^{a}$ UMR Innovation, Univ. Montpellier, Cirad, INRAE, Montpellier SupAgro, Montpellier, France.

${ }^{b}$ CIRAD, UMR INNOVATION, 20071-003 Rio de Janeiro RJ, Brazil.

c UFRRJ Universidade Federal Rural do Rio de Janeiro, 20071-003 Rio de Janeiro RJ, Brazil.

${ }^{d}$ University of Lausanne, STSLab, Institut des sciences sociales.

Acknowledgements: The authors would like to thank Jean-Pierre Bréchet, Ivan Dufeu, and Sophie Dubuisson-Quellier for their help in developing the position put forward in this article, the organisers of and participants in the Economies of Detachment Workshop in Toulouse for their comments on the first version, and Gabrielle Leyden for her translation of the French text.

\section{Notes on contributors}

Ronan Le Velly is a professor of sociology at Montpellier SupAgro and a member of its research unit on innovation (UMR Innovation). His research is at the crossroads of market sociology and rural studies and focuses on alternative agri-food networks such as fair trade, short food supply chains, and organic agriculture.

Frédéric Goulet is a researcher at CIRAD (French agricultural research and international development organisation) and a member of UMR Innovation. His research concerns technical innovation in agriculture and contemporary developments in agricultural research in France and South America.

Dominique Vinck is professor of Science and Technology Studies at the University of Lausanne, member of the STSLab. He directs the UNIL Institute of Social Sciences and the Doctoral Program in Digital Studies. His research focuses on the sociology of science and innovation. He is Chief Editor of the Revue d'Anthropologie des Connaissances. He published among other: Everyday engineering. Ethnography of design and innovation (MIT Press, 2003), The Sociology of Scientific Work. The Fundamental Relationship between Science and Society (Edward Elgar, 2010), Critical studies of innovation: Alternatives to the Pro-Innovation Bias (Edward Elgar, 2017). 


\title{
Allowing for detachment processes in market innovation. The case of short food supply chains
}

\begin{abstract}
The purpose of this paper is to study the place of detachment processes in market innovation. The authors draw on the case of short food supply chains, especially those established to provide local produce for mass catering. They characterise short food supply chains as "market innovations through withdrawal", i.e., market innovations aiming at detaching farmers and consumers from the middlemen of mainstream markets and reducing the number of food miles. They argue that detachment from mainstream market mediators generally calls for the creation of new mediators and highlight the difficulties of this agencing work. In line with research on path dependence, they also show that existing attachments may impede detachments. Finally, the authors show that short food supply chains combine the establishment of new detachments and new attachments, and the maintenance of pre-existing attachments and pre-existing detachments. They sum up this combination of processes with the term "quasi-detachment".
\end{abstract}

\section{Key words}

Local food, Market agencements, Market mediation, Market innovation, Mass catering

\section{Introduction}

Short food supply chains are a particularly fertile ground for working specifically on the place of detachment processes in the agencing of markets. The reason for being of short chains is effectively to set up direct local relations between producers and consumers, to detach them from the intermediate actors and devices that populate conventional supply chains (farm cooperatives, wholesalers, mass distribution, transport over long distances, "market prices", and so on). The aims of this detachment are to get fairer prices, to establish renewed social relations, to reduce the environmental impact of food, to eat healthier or more authentic food, etc. The overall aim, in a nutshell, is to improve the way agricultural and food networks work. As such, the detachment is the reason for being of the market innovation process.

Research at the crossroads of marketing and cultural studies has described local food consumption as a way to resist the mainstream food market and to assert alternative collective identities (Thompson and Coskuner-Balli 2007; Moraes, Szmigin, and Carrigan 2010; Autio et al. 2013; McArthur 2015; Huddart Kennedy, Parkins, and Johnston 2018). This work offers a deep understanding of local food consumers' motives and meanings. But, on the other hand, it does not deal with the agencing processes that establish new relationships between local producers and consumers. Yet, rural sociology studies have shown how much the construction of short food supply chains is not an easy task. Establishing closer, more local trade relations takes a great deal of work regarding both the practical organisation of the trade (order and delivery management, etc.) and the need to adapt production choices to meet consumer expectations (Jarosz 2008; Galt 2013; Dupré, Lamine, and Navarrete 2017).

The sociology of market agencements ${ }^{1}$ is a particularly promising theoretical approach to specifying all the conditions that are required to establish relocalised marketing chains and to

1 We use the term "sociology of market agencements" to label a series of works in market studies inspired by Actor-Network Theory that has also been associated with terms such as "economy of qualities" (Callon, Méadel, and Rabeharisoa 2002), "market devices" (Muniesa, Millo, and Callon 2007), "market work" (Cochoy and Dubuisson-Quellier 2013), and "marketization" (Çalişkan and Callon 2010). This research has grown considerably over the 
enable local food consumption. The sociology of market agencements is very mindful of the role of cultural narratives in this process (Geiger and Finch 2016), but also goes beyond that by taking a close look at the social relations and material devices that constitute and shape markets (Muniesa, Millo, and Callon 2007; Çalişkan and Callon 2010). Moreover, this analytical frame has been mobilised by researchers in rural studies these past few years. Their publications show clearly that the creation of national and international markets for major commodities (Ouma 2015; Henry 2017) and the creation of alternative networks (Onyas, McEachern, and Ryan 2018; Wang 2018) are both dependent on the difficult job of agencing markets. Seen from this perspective, charters and contracts, trucks and warehouses, packaging and leaflets, etc., can be as significant as people and meanings in the building of short food supply chains and local food consumption (Le Velly and Dufeu 2016; Le Velly and Moraine 2020).

This starting point offers stimulating perspectives. First of all, given this plan of detaching producers and consumers from the human and non-human intermediaries of long supply chains, one must know how market mediation will take place henceforward. We already know that such intermediaries do not just connect up pre-existing supply and demand, but take part in creating supply and demand (Cochoy, Trompette, and Araujo 2016). So, we can expect the elimination of these intermediaries or, rather, these "mediators" (Karpik 1996; Hennion 2015) to be a complicated process that will ultimately require the introduction of new intermediaries. Next, considering the short food supply chains to be market agencements prompts us to look at the human and non-human entities of which they are composed and to clarify the contours of the detached entities. It appears highly unlikely that the short chains are totally original arrangements devoid of all the elements of conventional chains. Investigations of "alternative food networks" (Goodman, DuPuis, and Goodman 2012), "diverse economies" (GibsonGraham 2008), and "alternative economic spaces" (Leyshon, Lee, and Williams 2003) converge in showing the same interest in observing the specific points upon which alternatives are built.

We shall develop our argument in six stages. We shall start by underlining the failure of the sociology of market agencements to pay attention to detachment processes. Even though this theoretical frame allows and encourages one to take account of attachments and detachments symmetrically, we shall see that the former have until now come in for much more study than the latter. The second part will be devoted to a general presentation of short food supply chains in France. In combining the notion of market innovation developed to allow for the agencing of new markets (Kjellberg, Azimont, and Reid 2015) with our notion of innovation through withdrawal (Goulet and Vinck 2012, 2017), we shall highlight that detachment is the reason for being of short food supply chains and characterise them as "market innovations through withdrawal". In the third part we shall specify the survey conditions upon which our article is based. In this step we shall see that we shall be working on a specific type of short supply chain, namely, chains set up to provide mass catering (e.g., in schools or hospitals) with local produce. In the fourth part we shall present the market mediation work involved to set up such chains and in the fifth part we shall answer our hypothesis that the existing attachments are binding and detachments do not occur easily. In coming back to the case of supplying catering services locally, we shall insist in particular on the weight of past material investments and of regulatory requirements. Finally, in the sixth part we shall show through our examples what these short

past ten years and been the subject of numerous publications, especially in the form of special issues and collective books (in addition to the previous references, see notably MacKenzie, Muniesa, and Siu 2007; Geiger et al. 2014; Cochoy, Deville, and McFall 2015; Kjellberg, Azimont, and Reid 2015; Cochoy, Trompette, and Araujo 2016). 
supply chains combine in terms of new and pre-existing attachments and detachments. We shall sum up this combination of processes with the term "quasi-detachment".

\section{The neglect of detachments in market innovation studies}

Even though the sociology of market agencements and Actor-Network Theory, from which it is derived, encourage the symmetrical study of attachment and detachment, research until now has above all given priority to the former (Le Velly and Goulet 2015).

Market agencing processes have been amply documented, but with emphasis on the operations that are aimed at generating new product qualifications, "qualculation" spaces, market encounters, and attachments (Çalişkan and Callon 2010; Kjellberg, Azimont, and Reid 2015; Cochoy, Trompette, and Araujo 2016; Callon 2017; Le Velly and Moraine 2020). Taking this perspective, several studies have also shown that framing-overflowing dynamics are vital critical springs for new agencings. Identifying and criticising overflowing, that is to say, elements that the existing framings fail to take account of (environmental pollution, farm poverty, exclusion of poor consumers, etc.), are the raison d'être for establishing new framings and thus markets (Geiger et al. 2014; Geiger and Gross 2018). Yet, whilst these works describe in fine detail the creation of new attachments, they fail for all that to explain how the actors detach themselves or are detached from the existing agencements. For example, Doganova and Karnøe show the extent of the framing work require to create a market for a technology to reduce the ammonia emissions of farms, but do not describe how the farmers subsequently did or did not accept to abandon their former technical solutions (Doganova and Karnøe 2015).

This blind spot is questionable. Losing sight of detachments would amount to neglecting a major teaching of science and technology studies, namely, the weight of lock-ins and path dependence (Garud and Karnoe 2001; Geels 2004) or, if not, to forgetting a founding challenge in sociology, that is, the weight of institutions (Durkheim 1982; Giddens 1984). Existing attachments are binding; detachments do not occur easily. In particular, whilst criticism can be thought of heuristically as a prime mover of innovation, it can remain without effect, without detachment, for a long time. For example, attachments to plastic bottles, shopping bags, palm oil, and pesticides persist despite all the criticism levelled at them (Hawkins 2011; D'Antone and Spencer 2014; Hagberg 2016, Author).

The study of detachments and attachments can also be a mooring point for grasping the dynamics of competition (Callon, Méadel, and Rabeharisoa 2002). However, on this issue, as well, the research conducted to date is relatively asymmetrical, focusing primarily on attachment techniques (Cochoy, Deville, and McFall 2015). The following excerpt from The economy of qualities illustrates this tendency:

"Competition between firms occurs precisely around this dialectic of attachment and detachment. Capturing, 'attaching' consumers by 'detaching' them from the networks built by rivals is the mainspring of competition. How does this form of detachment occur? Answer: by getting consumers to requalify the different products offered to them, that is, by repositioning a product in such a way that it becomes visible to consumers, so that they are prompted to embark on a new effort at evaluation." (Callon, Méadel, and Rabeharisoa 2002, 205)

In these lines, Callon and his co-authors draw our attention to the importance of detachments. Yet, upon explaining how detachments occur, they highlight only the new assessments and new attachments that must be made for the consumer to turn to new products. In the example of orange juice that follows, it is as if proposing a new attachment suffices for the old attachments to break. We might expect studies working on the "captation" of customers (Cochoy 2007), or capturing customers, to be more attentive to the operations by means of which the customers 
are turned away from the products or suppliers to which they are attached. That is not borne out, however. It is due to that fact that in some cases the studied customers were newcomers to the market, i.e., previously unattached individuals (Trompette 2007), and in other cases people who were already, albeit weakly, attached to their suppliers (Deville 2012).

Studying attachment is not sufficient to understand detachment, for the two processes are quite separate in practice. In a previous article (Le Velly and Goulet 2015), we described the operations whereby the technical sales staff of an alternative agricultural supply firm managed to detach farmers from the inputs that they used up to then. Their actions were aimed at changing the farmers' assessment frameworks in order to make their products and the changes in agricultural practices that accompanied their use (no-till farming) more attractive. But they also had a complementary aim, that of breaking the solid ties that the farmers had with their usual suppliers. To do that, these sales reps used specific messages criticising the scientific foundations, advisory relations, and commercial relations supporting the existing attachments. The two processes of detachment and attachment could thus be seen to be quite distinct.

To wrap up on this, let us point out that this matter of detachment must not be mistaken for disentanglement, which is just as central in the sociology of market agencements. In using the term "disentanglement", Callon emphasised the operations allowing a good to acquire objective qualities and to be separated from its vendor. Disentanglement, even temporary disentanglement, is indispensable if the calculation and transfer of merchandise is to be possible (Callon 1998, 2017; see also Slater 2002). Disentanglement is thus a process that helps to frame markets, not one that destroys existing framings. It is thus on the side of attachments, not detachments.

\section{Short food supply chains as market innovations through withdrawal}

The term "short food supply chains" refers to a very diverse range of practices, such as direct sales on the farm, vegetable box subscription schemes, farmers' markets, and so on (Kneafsey et al. 2008). Yet for all that, two characteristics are usually required to talk about "short" chains, namely, a reduction in the number of intermediaries and a reduction in the number of food miles covered. With regard to the first point, the French Ministry of Agriculture and Food defines a short chain as containing no or one intermediary. As for food miles, there is no unanimously recognised minimum distance, but the operators themselves often agree on a radius of some $100 \mathrm{~km}$ (60 miles) for fruits and vegetables or the administrative region for meat products. Short food supply chains are then intimately connected to the "eat local" movements or "locavorism" that is spreading through most Western countries.

The two dimensions of the "short chain" are very often combined in practice. Yet the two detachments gain from being thought of separately. Certain supply chains thus have no intermediaries but are geographically long. Typical examples are direct sales of foie gras and wine at fairs and over Internet sites. Above all, it is not rare for the selling of local produce to involve the work of several intermediaries (Ilbery and Maye 2005). For example, before going to an open-air market or to compose the boxes that they are going to deliver, certain producers top up their assortments with produce from wholesalers, and not always with the consumers' knowledge. Objectives of transparency then arise and can spawn the creation of innovative market devices (Chiffoleau, Millet-Amrani, and Canard 2016).

Short food supply chains are exemplary of what we have called "innovations through withdrawal" (Goulet and Vinck 2012, 2017). In such forms of innovation, detachment is not just a step that occurs prior to attachment; it is its reason for being. The development of foods without preservatives, of car-free cities, and of no-till farming are three cases that illustrate this form of innovation "through withdrawal" quite well. In contrast to a common definition of innovation that assumes the addition of certain entities, studying innovations aimed specifically 
at removing things is very worthwhile, for such innovations offer particularly clear insights into detachment processes.

Speaking about "market innovations through withdrawal" to talk about short food supply chains is relevant, for creating such innovative market relations amounts to producing reductions on two fronts, i.e., in the number of intermediaries and in the number of miles covered. In both senses of this "shortening", it involves removing or eliminating attachments that give shape to the "long supply chains". The aim is to detach oneself from the large agricultural businesses and cooperatives, agri-food industry and its preservation and processing processes, industrial slaughterhouses and long-distance transport, and supermarket chains and fast-food restaurants. To weaken the ties to these intermediaries discursively, the messaging associates them with a host of problems: environmental pollution, health crises, farm poverty, animal abuse, deteriorating food quality, addition of undesirable ingredients, etc. Some of the critics focus on the intermediaries' actions, whereas others target the long distances covered, but all of the criticism converges in the overall criticism of long chains. The opposite applies to short chains: Participating in short chains is associated with a long list of benefits that includes renewed social relations between producers and consumers, cognitive reconnections between agriculture and food, democratic governance of agri-food issues, respect for the environment, better remuneration for farmers, healthy and authentic products, and so on. All of these "promises of difference" are generally put forward by the advocates of short supply chains (Le Velly 2019), even though, in practice, these benefits are far from always achieved (Born and Purcell 2006; Huddart Kennedy, Parkins, and Johnston 2018).

\section{Methods}

The rest of this article will focus on a specific type of short food supply chain, namely, the chains established to supply mass catering. This subject has been an item resolutely included in the public agenda in France for about a decade. The local administrations responsible for school meals up to the end of secondary school almost unanimously agree with the policy of including local produce in school menus. New intermediaries have sprung up everywhere: farmers have founded collective organisations to try to meet the demand, Internet platforms have been created to make it easier to match local suppliers with local demand, contract catering companies have started to include local producers in their lists of suppliers, and so on. The State is also encouraging this movement. The successive governments in power in 2010, 2014, and 2018 thus enshrined various objectives of including local products in institutional meals in their agricultural acts. Even though these targets were not accompanied by binding legislation or incentives, they have set symbolic compass headings for agricultural operators and contract caterers to follow.

The lead author of this article has been conducting field investigations into supplying mass catering services locally for the past ten years. Between 2008 and 2012 he assisted the central kitchen of the city of Nantes (12000 school meals per day) with the steps it was taking to develop its local supply network. To this end, he participated in the steering committees of various actions, supervised a student intern, and conducted a dozen semi-structured interviews with the stakeholders in the actions being carried out. In 2009 he was also a member of a working group of some forty elected officials and managers from cities in western France that was set up to work on providing public meal services with local organic food supplies. The work of this group led to several monographs, including one dedicated to the actions by the City of Brest (6000 school meals per day), and the publication of a practical guide explaining the constraints upon and levers for developing local and organic food procurement. From 2012 to 2017 the lead author worked more specifically on the operation of a dozen regional organic farming organisations set up to supply a large range of local and organic produce to institutional 
food services. This work took the form of participating in project steering committees and conducting ten interviews, amongst other things. It has led to a thematic analysis of the similar organisational issues that all these local platforms face and the very varied practical responses that their promoters give from one platform to another (for produce transportation, catalogue price setting, etc.).

These experiences will be used in the subsequent sections of this article to reveal their crosscutting teachings. This choice will have the disadvantage of decontextualizing our remarks, of not situating the observed initiatives in their social history. On the other hand, it will enable us to step back from events and to propose a general analysis of the detachment processes at work in the agencing of these short food supply chains.

\section{From withdrawal to adding new market mediations}

\section{Even short food supply chains require market mediations}

"Market mediation" holds an important place in the sociology of market agencing, especially in the first works published in French. The use of the term "mediation" in reference to actornetwork theory (Latour 2005; Hennion 2015) was aimed at stressing the fact that the human and non-human entities that come between producers and consumers do not connect up a supply and demand that are "already there" but establish the supply, demand, and market in the same dynamic (Karpik 1996; see also Cochoy, Trompette, and Araujo 2016). For example, the advertising, points of sale, packaging, and vendors take part in educating consumers, change the scope of choice, and weigh upon consumption practices (Mallard 2012; Geysmans, de Krom, and Hustinx 2017; Cochoy 2018). Similarly, consumer tests influence what the supply will finally be (Hennion 1983; Callon, Méadel, and Rabeharisoa 2002; Dubuisson-Quellier 2010). Even more clearly, purchasing guides, such as the Michelin Guide or those that are written by environmental activist associations, affect demand by educating and equipping consumers (see also Fuentes and Sörum 2019), but also affect supply by establishing a reference framework of practices that are assumed to be expected by a growing number of people (Karpik 2000; Dubuisson-Quellier 2013). This mediating role can be extended to the entire set of market devices and "market professionals" (Cochoy and Dubuisson-Quellier 2013), in short and long chains alike.

The presence of farmers wishing to sell via short chains and mass catering managers wishing to consume locally in a given area are not sufficient conditions for a market between the two to exist. Here the idea of market mediation translates the feeling of helplessness that many farmers and cafeteria managers feel when they become aware of the distance that they must still cover before they can trade with each other directly. This inability refers to a phenomenon of distributed agency, i.e., the ability to buy and sell directly and locally depends on a set of components forming a market agencement that is not limited to a group of predetermined producers and consumers (Çalişkan and Callon 2010).

Let's take the example of the establishment of a short chain to supply farm poultry to the central kitchen of the city of Nantes. Three rounds of experiments had to be carried out to adjust all the pieces in the puzzle before the supply chain could become stable. For example, the city's central kitchen had to revise its cooking methods twice before it found the right procedure. During the first round, the central kitchen cooked the cuts of 120-day chickens at high temperatures, exactly in the same way as they had previously cooked the usual 38-day-old poultry. This resulted in extremely dry, tough meat that the canteens' children could not cut and eat. After two other tests, the manager of the central kitchen finally found the solution: lowering the temperature, lengthening the cooking time, and fricasseeing the poultry on trays rather than on grills. The poultry farmers also had to rethink their farming practices in order to get chickens of a uniform size that could be carved into ten pieces of constant weight. They also had to 
rework their slaughtering and delivery schedules in order to comply with health regulations. During the first experiment, the parcels delivered to the central kitchen were not sufficiently cold $\left(5-6^{\circ} \mathrm{C}\right.$, instead of the $0-2^{\circ} \mathrm{C}$ prescribed by hygiene standards) and did not all include exactly the same number of pieces, a situation that, in principle, should have resulted in their automatic refusal.

Even with simpler produce, such as carrots, apples, yoghurt, and so on, the actors raise mediation questions that must be answered, e.g., defining quality, grade, packing, prices, schedules, delivery methods, and so on. All of these points, which refer back to the various "marketization" processes mentioned by Callon (Çalişkan and Callon 2010; Callon 2017), must be settled before the market can exist.

It should be pointed out that, in contrast, it is easy for a cafeteria manager to find no matter what product at no matter what time of the year from the distributors, such as Pomona, Brake, and Transgourmet, that normally supply school cafeterias. These distributors propose a complete range of products, even organic ones, from a host of supply chains. The intermediaries in these long supply chains do a huge amount of mediation (Bernard de Raymond 2013; Michel et al. 2019). Try to evict or bypass these players and their tools and you will quickly get an idea of what a mammoth job that is.

\section{Building platforms dedicated to supplying mass catering}

Many farmers' organisations have been created in the French organic agriculture sector to cope with these mediation problems. So, in 2020 there were some twenty organisations spread over various French administrative departments and regions, e.g., "Auvergne Bio Distribution", "Manger Bio en Vendée", etc. The aim of these farmers' organisations is to create a relatively vast commercial supply of local products that is adapted to the customary practices of institutional meal services. Cafeteria managers can then make a single order and pay a single invoice rather than contracting with a dozen local producers. These platforms usually offer a range that includes at least fruit, vegetables, beverages, and dairy and meat products. They sometimes also include grocery products, usually products that they themselves get from other wholesalers. They also make efforts to offer appropriate package sizes (five-litre tubs of yoghurt, carrots of a very specific grade, for example) and sales prices in line with the buyers' references and budgets. Finally, they give buyers and producers alike guarantees regarding administrative procedures (responses to public calls for tenders, order and invoice management) and logistic operations (warehousing, packaging, delivery, and cold chain integrity).

The creation of these platforms does not entail simply creating a common sales structure or even just investing in a warehouse and lorry. To realise that, it is interesting to observe the work that their managers do. A strategic dimension of this work concerns the creation of the platform's commercial offer, which takes the shape of a market device, i.e., the platform's catalogue. To do this, the platform managers must select those farmers in the collective who will be the most able to produce a given product. They also frequently have to act upon these farmers to get them to modify their farming practices (to grow the vegetables that the customers want, change their packaging, revise their grading, etc.). Setting the sales prices printed in the catalogues is also tricky. So, it is tempting, in response to the criticism levelled at long supply chains, to set "remunerative" sales prices calculated from production costs. And yet, that often proves unfeasible, because a given product in a given catalogue may come from different farmers with different production costs, the farmers do not know their exact production costs, or the catalogue prices must also allow for the prices set by their competitors.

In a word, in agencing innovative markets, detachment from existing market mediators generally calls for the creation of new mediators. This lesson must not lead us to conclude that all these actors are merely "reinventing the wheel". It would be more correct to say that they 
are trying to invent a new wheel, one that is suited to achieving the new ends asserted in short value chains. So, even though organic farmers' organisations end up using the conventional devices of market mediation (catalogues, grades and standards, warehouses and lorries, and so on), the new agencements' abilities to act are not the same as those of the pre-existing ones. First of all, these agencements are at the very least able to relocalise mass caterers' procurement sources. This should be stressed, for conventional supply chains usually are not able to guarantee local origins (see Part 5), and traditional short food supply chains have a hard time satisfying a clientele that needs to be able to order assortments. Next, the organic farmers' platforms are often motivated by the idea of including different types of farmer, ranging from diversified market gardeners working small plots of land to specialised, mechanised vegetable farmers. In this regard, the actors in the organic farming world defend the diversity of cropping systems, a goal that they feel is threatened in long supply chains. The work that goes into composing the catalogue may then reflect this end.

For example, the manager of Manger Bio en Vendée told us that he took account of this to determine which farmer would be responsible for a given product platform:

"If I need carrots, I take less from the one who has the highest production costs because this part of his production work is not at all mechanised. We'll prefer him for beets and celery, because he'll make out better price-wise" (interview, February 2013, conducted by Laurent Le Grel and Julien Noël).

This rule enables him ultimately to keep working with farmers with different technical profiles whilst proposing remunerative outlets for each of them and to create a catalogue with competitive prices.

\section{Constraints that limit possible detachments}

The elements that we have just presented underline one difficulty of detaching in agencing new markets, namely, the work that is necessary to reconstruct market mediation. In this part we shall emphasise another difficulty, the fact that existing attachments are binding or constraining; they thwart the innovation process. It is important to show this, given the risk of sociology of market agencements' being erroneously perceived as supporting the image of a perfectly malleable market system. Whilst market innovations are possible, the space for such possibilities is not open to the same extent in each situation.

\section{Attachments that limit innovation}

The observed initiatives to supply mass catering facilities locally show first of all that existing attachments thwart innovation. The problem is thus the classic one of lock-ins and path dependence (David 1985). This issue, which is well known in science and technology studies and has been tackled in recent years through the prism of sociotechnical transition mechanisms (Geels 2004), has curiously been given short shrift in the sociology of market agencements. Callon refers to it in his introduction to The Laws of the Markets (Callon 1998) and calls upon sociologists to rework these phenomena, which he deems vital for understanding framingoverflowing mechanisms and market dynamics, in a few lines included in his latest book (Callon 2017). We support this appeal.

Working on these forms of path dependence amounts to studying how existing attachments limit possible detachments. The constraints that are generated by the material investments of collective kitchens are particularly illustrative of this. Over the past fifteen years, most large and mid-sized cities and communities have invested in facilities tailored to assembly cooking, that is, assembling already prepared components. For example, the large and mid-sized central kitchens no longer have vegetable processing areas ("prepping stations") or bakeries. That means that they have to find ready-to-use vegetables (carrots that have been washed, peeled, 
had their ends snipped off, even been grated) and baked goods (cakes, etc.). Now, local farmers rarely propose such products and turning to industrial operations or distributors often means having no guarantee as to the local provenance of the foods. Leaving the habitual food supply chains thus proves more complicated than foreseen. A platform of farmers with a shared prepping facility must be available locally or else the procurers must envision the longer-term solution of modifying their kitchen facilities.

Next, procurement in an overwhelming number of cases is governed by multi-annual contracts. The managers of public central kitchens must turn to suppliers who have already been awarded contracts for specific tenders. For example, they will not be free to buy yoghurt from a local dairy for the three or four years for which the "dairy products" procurement contract is awarded to a specific distributor or industrial supplier. It should be noted, moreover, that this way of working is also found in the major private contract catering companies such as Sodexo and Elior. These companies have national reference policies that are aimed at getting low prices and ensuring perfect traceability and hygiene. Meal service managers have very little room for manoeuvre when it comes to buying from local producers (for a similar observation in hospital food procurement, see Klein 2015). For example, in one of these companies, restaurant managers may not decide alone to buy from a local farmer or group of farmers not on the list. If a customer makes a specific request for local produce, then the restaurant site manager must turn to his/her regional purchasing manager, who will decide according to a three-step decisionmaking rule: Is there already an equivalent product in the approved suppliers catalogue? If not, does this customer's specific request cover a large enough volume to warrant initiating additional referencing? If so, will the new supplier be able to meet the traceability and quality requirements imposed on all of the contract catering company's suppliers?

\section{Market infrastructures that limit detachment}

Other constraints are linked to the infrastructures and regulations that strongly regulate the institutional food services sector. In this second case, the field of possible detachments is determined not so much by past local choices as by the vast set of "market infrastructures" (Finch, Horan, and Reid 2015; Mellet and Beauvisage 2019) over which the actors have no direct control.

Let us first highlight the constraints generated by the ways in which food distributors are currently organised. In the preceding part, we highlighted how companies such as Pomona operate: Their well-oiled operating mechanisms enable catering service managers to buy a broad and diversified range of products all year 'round. And yet, we can also stress the fact that this supply comes from chains that are not designed to propose local product ranges that are differentiated according to the territory. This is something that may have to change. Most of the distributors that supply contract caterers and institutional food services announced in the $2010 \mathrm{~s}$ that they intended to meet this new demand from their customers. It will be interesting to see in the future how they go about this and how this goal of relocalising procurement will tie in with the ends that until now have prevailed in their organisational models. However, at the time of our investigations, it was impossible for them to guarantee the local or regional provenance of if only a tiny range of products within the framework of their usual organisational schemes.

Regulation is also a key element of the market infrastructures that may constrain the agencing of new markets (Pellandini-Simányi and Vargha 2019). Let us mention first of all the body of texts known as the "hygiene package", some strands of which concern food purchases. The latter must in particular be perfectly traceable and guarantee observance of the cold chain. This requires the suppliers in particular to take account of these factors in their storage and transport operations and the kitchens to carry out systematic inspections when their merchandise arrives. These obligations complicate greatly the work with local producers, who are often trained little 
and poorly equipped to comply with these procedures (see Laforge, Anderson, and McLachlan 2017). Next, providers of French school meals must follow official nutritional recommendations that govern the make-up of the menus proposed. For example, they must include raw fruits or vegetables as a starter or garnish in at least one of two menus. For some of the canteen managers whom we met, it then becomes difficult to serve only what is in season and to reduce food miles, unless they take the risk of serving raw and cooked vegetables that the children are unfamiliar with and/or do not like, a risk that is especially great in winter. Finally, for public institutional food services, procurement is also straitjacketed by the public procurement code, which strictly forbids giving priority to local suppliers. Government buyers may not include the requirement of local origin in their calls for tenders, nor may they even weight local provenance positively in calculating the scores that serve to award the contract. That would be completely contrary to two fundamental principles of public procurement, namely, freedom of access to public procurement contracts and equal treatment of all bidders.

Taking all of these constraints on detachment into account is vital. Yet, to wrap up this section, we must also point out that these constraints must not be seen as pure hobbles on innovation. The term "lock-in", which is also used to describe these phenomena, is misleading if it suggests a perfectly stymied situation. In the case at hand, the players likewise act to overcome or circumvent the constraints. For example, certain towns put forward the experimental nature of a one-off local purchase so as not to have to issue a call for tenders and circumvent the supplier that has been awarded the contract. Such an approach, which is supposed to be temporary, may occasionally become lasting without the "official" supplier's contesting it in order to avoid angering the municipal administration. Much is also negotiated informally, alongside the official procedure. It is possible, for example, for a town or institution to tell a distributor or wholesaler orally that it wants to receive seasonal regional products. When it comes time to renew the contract, this message can also be broadcast by requiring that the contenders provide a technical report describing their supply schemes.

\section{Quasi-detachments}

The previous two parts attest to the difficulties of detachment but also show how detachment remains possible in establishing innovative market agencements. We shall now refine this second point by introducing an additional argument. Market innovation combines four processes: i) establishing new detachments and ii) establishing new attachments, but also iii) maintaining existing attachments and iv) maintaining existing detachments. Of these four processes, the fourth one is definitely the most unexpected, for how does one take account of maintaining ties that do not exist? And yet, guided by our desire to conduct a strictly symmetrical analysis, we propose following this heuristic rule. The combination of these four processes is what we shall call, quite simply, a "quasi-detachment". The agencing of new markets, even of those that are guided by a desire to withdraw elements, such as short supply chains, usually does not entail renewing all the attachments. It does not entail cutting all ties and many of the pre-existing detachments are not challenged, either.

To show this, we shall rely on another interesting case: the supply chain initiated by the central kitchen of the city of Brest, in western France. This supply chain is original in that it is both very local, since all the players are located within $150 \mathrm{~km}$ (less than 100 miles) of Brest, and involves a high degree of intermediation. So, it involves six players: 1) Bio Breizh, a cooperative of 60 organic fruit and vegetable farmers in northern Brittany whose produce is sold mainly in long supply chains (networks of specialised organic shops, supermarkets, and so on); 2) Poder, a first trade intermediary that collects the produce at the farmers' gates, sorts the produce, and hauls it to La Légumière; 3) La Légumière, an agrifood processing shop that turns the crude produce into ready-to-use products (grated carrots, for example); 4) Le Saint, a second 
trade intermediary that is a fruit and vegetable distributor and member of the national network Vivalya; 5) Sodexo, the multinational contract caterer to which the municipality of Brest entrusts the running of its central kitchen; and 6) the city of Brest which, through its school cafeterias, serves some 6,000 meals a day. This agencement results from the maintenance of existing attachments and detachments and the creation of new detachments and attachments.

\section{Maintaining existing attachments and detachments}

Let's start with the first process. If we scrutinise the trade relations, it is possible to say that the new supply chain is rooted in pre-existing relations: The farmers in Bio Breizh have been working with Poder with great confidence for many years and Le Saint is Sodexo's fruit and vegetable supplier for the central kitchen of Brest. This supply chain also relies on the infrastructure of the parties involved. The farmers had no need to make any investments in either lorries or warehouses and Sodexo did not have to set up a new vegetable prepping station in its central kitchen. Let us add to this material infrastructure the skills of all the players, who are professionals of the various market mediation operations that are involved. These skills likewise remain.

The second process seems more difficult to observe, but it is not all that difficult if we consider from this angle the choices made by the players who built the new agencement. This agencement is thus a consequence of the Bio Breizh farmers' wish to continue to detach themselves from direct relations with the final customers. These farmers, who usually work in chains with various middlemen, were initially called upon directly by the city of Brest to supply produce, but they felt that it would be too complicated for them to get involved in direct relations with the end-users. The central kitchen continued in the same way to detach itself from the plant necessary to process the raw, unprocessed produce in the new agencement that was built. Such a choice is not seen everywhere. Certain communities, such as the city of Nîmes (southern France), have, on the contrary, restructured their central kitchens to include a vegetable prepping area.

\section{Establishing new detachments and attachments}

Despite the continuation of all these existing ties and non-ties, detachments were made to generate innovation. One noteworthy detachment is the one made by Le Saint from the long supply chains that supplied it before this agencement was created. So, initially, Le Saint supplied Sodexo with organic carrots and potatoes from Italy or the Netherlands, including at the height of these crops' local production seasons.

The establishment of new attachments made these detachments possible. The new connections amongst Poder, La Légumière, and Le Saint are key in this regard, especially as they do not concern merchandise flows only. At the time that this new agencement was established, the city of Brest thus imposed regular participation in a "monitoring group" on all of the supply chain actors, the goal of this group being to discuss the organisational matters that concerned them. Its aim at the time was to create within this framework different relations from those that characterise long supply chains. This group does indeed help to solve collectively the problems encountered over the year, for example, in the case of problematic weather and poor harvests. Rather than having such events result in breaches of contract, the monitoring group considers solutions for the ongoing season and following years. As such, it is a vector for learning, and the market agencement becomes a learning agencement. Finally, the monitoring group generates additional transparency compared with the degree of opacity that chains with a large number of intermediaries usually offer. The fact that matters are discussed publicly avoids giving the intermediaries in the supply chain the possibility of manipulating information to their advantage, for example by claiming that the quality provided falls short of the mark. 
The agencement established by the city of Brest is singular in terms of both its shape and its capability for action. Yet the finding in this case that short supply chains are established by quasi-detachment has a very general scope. To show this, we can refer to the findings of a wealth of rural sociology investigations into short supply chains. This research tells us first of all that the presence of intermediaries in short supply chains is not at all unusual, including in the more usual short chains such as open-air markets and vegetable box subscription schemes (Clarke et al. 2008; Chiffoleau, Millet-Amrani, and Canard 2016). Short food supply chains are "hybrid" networks that blend the alternative and the conventional (Ilbery and Maye 2005; Le Velly and Dufeu 2016) and piggy-back on long-chain infrastructure such as slaughterhouses and wholesalers (Clark and Inwood 2016). Rural sociology research also underlines how much the prices practised in long supply chains influence price-setting in short supply chains (Galt 2013; Mundler 2013). The actors in short supply chains observe the prices practised in supermarkets or specialised organic shops as much for reasons of competition (so as not to set commercially unreasonable prices) as for pragmatic reasons (to have cognitive landmarks for setting their prices). In a process that is reminiscent of the one described by Çalişkan (Çalişkan 2007), they remain partially attached to the "market prices" of long supply chains. Attachment to the quality standards of long supply chains can also be put forward. The consumers who patronise short supply chains are not always ready to eat products that differ greatly from the ones that they find in supermarkets and remain attached to being offered a diversified range (Cleveland et al. 2014). All of these investigations converge in finding that short supply chains are not a different breed of market agencements separate from long supply chains, but rather hybrid market agencements involving quasi-detachments from long chains.

\section{Conclusions}

By looking at short food supply chains through the prism of "innovations through withdrawal", we emphasised the fact that these market innovations strive to eliminate or to reduce the trade intermediaries and food miles that divide producers from consumers. In the messages put out by their promoters, this withdrawal is associated with the promise of a great many advantages that solve just as many of the problems associated with "long supply chains". This discourse, which is forged on the anvil of opposition between the "short chains" and "long chains" categories, is a driver of change; it is a vector of market innovation.

Yet for all that, when we go from observing this discourse to observing the market agencing processes involved, another result emerges. It becomes clear that withdrawing from long supply chains can be done in many ways, via a host of configurations that all have one element in common, the process that we have called "quasi-detachment". The sociology of market agencements offers on this point an analysis that is more aware of the mixed, hybrid nature of short food supply chains than the cultural analysis that stresses the resistant and alternative identities of local food consumers. Local food consumption may be motivated by a strong desire for alternativeness but, at the same time, short food supply chains deserve to be analysed as "hybrid spaces" (Ilbery and Maye 2005) involving a mix of mainstream and alternative actors, rules, and devices (Le Velly and Dufeu 2016). The capacities for action of short chains then cannot be postulated or reduced to the promises made in the discourse of those who promote them. Rather, they depend on the entities and relations that compose each chain.

Working on this case of innovation through withdrawal was an opportunity to examine very specifically the place of detachments in market innovation. Three general lessons on detachment may be drawn to end this paper.

First, current attachments are sticky and binding. It is difficult to detach oneself from current ties and to establish new ties, even when the existing attachments are not totally satisfying. This first lesson echoes classical thinking about institutions and more recent research on lock-ins 
and path dependence, but it is a not-so-obvious lesson for market studies. Markets agencements can be made and remade, but they are not totally flexible and market innovation has to deal with existing socio-technical arrangements. Several recent studies of market innovation have noted that the reframings that are done do not always reach their promoters' objectives. They underlined that agencing markets was a process that some actors did not master and might be contested by resisting or circumventing devices established by other parties (Hébert 2014; Cochoy, Trompette, and Araujo 2016; Geiger and Gross 2018). In our opinion, an additional explanation for these failures is to be sought in the lock-ins and constraints imposed by the socio-technical arrangements in place.

Second, as already suggested by the case of adopting no-tilling practices in farming (Goulet and Vinck 2012) and the development of alternatives to pesticides (Aulagnier and Goulet 2017), detachment from certain entities generally requires attachment to other entities. For instance, "market innovations through withdrawal" such as short food supply chains do not remove all market mediators. Rather, they change some of them. This second conclusion may seem obvious, as the opposite would have been surprising: there is no such thing as markets without any attachments. It is nevertheless worthwhile if we compare it with the discourses that usually accompany the promotion of innovations through withdrawal. By focusing on the entities that are detached (no preservatives, no gluten, no pesticides, sugar-free, etc.), these discourses tend to hide the attachments that were made to allow withdrawal. Researchers must thus go beyond the public discourse and observe the new attachments, the "withs" that accompany these innovations. From a more political or moral standpoint, this means that detachment should not be thought of as an end in itself, but as a process aimed at detaching oneself from contested entities and attaching oneself to more desirable ones.

Third, even with innovation through withdrawal, detachment processes are always partial; they are in fact "quasi-detachments". This last lesson also has political implications, which, what is more, are in line with Gibson-Graham's perspective on "diverse economies" (Gibson-Graham 2008). Rather than opposing a bad attached world to a good detached world, it suggests that detachment processes can engender multiple possible market agencements, with various capacities to act. In this perspective, building a more sustainable economy does not necessary involve a detachment from the usual suspects, i.e., big businesses or middlemen. What is at stake is much more the development of a "political engineering" (Callon 2017) of market agencements that pays attention to the networks of actors and devices of which they are made and gives them the ability to act, so that they can fully reach the sustainability objectives that we give them.

\section{References}

Aulagnier, Alexis, and Frédéric Goulet. 2017. "Des technologies controversées et de leurs alternatives. Le cas des pesticides agricoles en France." Sociologie $d u$ Travail 59 (3):online.

Autio, Minna, Rebecca Collins, Stefan Wahlen, and Marika Anttila. 2013. "Consuming nostalgia? The appreciation of authenticity in local food production." International Journal of Consumer Studies 37 (5):564-8.

Bernard de Raymond, Antoine. 2013. En toute saison: le marché des fruits et légumes en France. Rennes: Presses universitaires de Rennes.

Born, Branden, and Mark Purcell. 2006. "Avoiding the Local Trap: Scale and Food Systems in Planning Research." Journal of Planning Education and Research 26 (2):195-207. 
Çalişkan, Koray. 2007. "Price as a Market Device: Cotton Trading in Izmir Mercantile Exchange." The Sociological Review 55 (S2):241-60.

Çalişkan, Koray, and Michel Callon. 2010. "Economization, part 2: a research programme for the study of markets." Economy and Society 39 (1):1-32.

Callon, Michel. 1998. "Introduction: the embeddedness of economic markets in economics." The Sociological Review 46 (S1):1-57.

. 2017. L'emprise des marchés. Comprendre leur fonctionnement pour pouvoir les changer. Paris: La découverte.

Callon, Michel, Cécile Méadel, and Vololona Rabeharisoa. 2002. "The economy of qualities." Economy and Society 31 (2):194-217.

Chiffoleau, Yuna, Sarah Millet-Amrani, and Arielle Canard. 2016. "From Short Food Supply Chains to Sustainable Agriculture in Urban Food Systems: Food Democracy as a Vector of Transition." Agriculture 6 (4):on line.

Clark, Jill K., and Shoshanah M. Inwood. 2016. "Scaling-up regional fruit and vegetable distribution: potential for adaptive change in the food system." Agriculture and Human Values 33 (3):503-19.

Clarke, Nick, Paul Cloke, Clive Barnett, and Alice Malpass. 2008. "The spaces and ethics of organic food." Journal of Rural Studies 24 (3):219-30.

Cleveland, David A., Nora M. Müller, Alexander C. Tranovich, D. Niki Mazaroli, and Kai Hinson. 2014. "Local food hubs for alternative food systems: A case study from Santa Barbara County, California." Journal of Rural Studies 35 (1):26-36.

Cochoy, Franck. 2007. "A Brief Theory of the 'Captation' of Publics: Understanding the market with Little Red Riding Hood." Theory, Culture \& Society 24 (7-8):20323.

-. 2018. "'Making people buy and eat differently": lessons from the modernisation of small independent grocery stores in the early twentieth century." Review of Agricultural, Food and Environmental Studies 99 (1):15-35.

Cochoy, Franck, Joe Deville, and Liz McFall. 2015. Markets and the Arts of Attachment. London: Routledge.

Cochoy, Franck, and Sophie Dubuisson-Quellier. 2013. "The sociology of market work." Economic sociology the european electronic newsletter 15 (1):4-11.

Cochoy, Franck, Pascale Trompette, and Luis Araujo. 2016. "From market agencements to market agencing: an introduction." Consumption Markets \& Culture 19 (1):316.

D'Antone, Simona, and Robert Spencer. 2014. "Concerns and Marketization: the case of Sustainable Palm Oil." In Concerned Markets Economic Ordering for Multiple Values, edited by Susi Geiger, Debbie Harrison, Hans Kjellberg and Alexandre Mallard, 72-101. Cheltenham: Edward Elgar.

David, Paul A. 1985. "Clio and the Economics of QWERTY." The American economic review 75 (2):332-7. 
Deville, Joe. 2012. "Regenerating market attachments. Consumer credit debt collection and the capture of affect." Journal of Cultural Economy 5 (4):423-39.

Doganova, Liliana, and Peter Karnøe. 2015. "Building markets for clean technologies: Controversies, environmental concerns and economic worth." Industrial Marketing Management 44 (1):22-31.

Dubuisson-Quellier, Sophie. 2010. "Product tastes, consumer tastes: The plurality of qualification in product development and marketing activities." In Reconnecting marketing to markets, edited by Luis Araujo, John Finch and Hans Kjellberg, 7493. Oxford: Oxford University Press.

. 2013. "A market mediation strategy: How social movements seek to change firms' practices by promoting new principles of product valuation." Organization Studies 34 (5-6):683-703.

Dupré, Lucie, Claire Lamine, and Mireille Navarrete. 2017. "Short Food Supply Chains, Long Working Days: Active Work and the Construction of Professional Satisfaction in French Diversified Organic Market Gardening." Sociologia Ruralis 57 (3):396-414.

Durkheim, Emile. 1982. The rules of sociological method. New York: The free press.

Finch, John, Conor Horan, and Emma Reid. 2015. "The performativity of sustainability: making a conduit a marketing device." Journal of Marketing Management 31 (12):167-92.

Fuentes, Christian, and Niklas Sörum. 2019. "Agencing ethical consumers: smartphone apps and the socio-material reconfiguration of everyday life." Consumption Markets \& Culture 22 (2):131-56.

Galt, Ryan E. 2013. "The Moral Economy Is a Double-edged Sword: Explaining Farmers' Earnings and Self-exploitation in Community-Supported Agriculture." Economic Geography 89 (4):341-65.

Garud, Raghu, and Peter Karnoe. 2001. Path dependence and creation. Mahwah: Lawrence Earlbaum Associates.

Geels, Frank W. 2004. "From sectoral systems of innovation to socio-technical systems: Insights about dynamics and change from sociology and institutional theory." Research policy 33 (6):897-920.

Geiger, Susi, and John Finch. 2016. "Promissories and pharmaceutical patents: agencing markets through public narratives." Consumption Markets \& Culture 19 (1):7191.

Geiger, Susi, and Nicole Gross. 2018. "Market Failures and Market Framings: Can a market be transformed from the inside?" Organization Studies 39 (10):1357-76.

Geiger, Susi, Debbie Harrison, Hans Kjellberg, and Alexandre Mallard. 2014. Concerned Markets. Economic Ordering for Multiple Values. Cheltenham: Edward Elgar.

Geysmans, Robbe, Michiel P. M. M. de Krom, and Lesley Hustinx. 2017. "“Fairtradization": a performative perspective on fair trade markets and the role 
of retail settings in their enactment." Consumption Markets \& Culture 20 (6):53958.

Gibson-Graham, J.K. 2008. "Diverse economies: performative practices for 'other worlds'." Progress in Human Geography 32 (5):613-32.

Giddens, Anthony. 1984. The constitution of society. Outline of the theory of structuration. Cambridge: Polity Press.

Goodman, David, Melanie DuPuis, and Michael Goodman. 2012. Alternative food networks. Knowledge, practice and politics. London: Routledge.

Goulet, Frédéric, and Dominique Vinck. 2012. "Innovation through Withdrawal. Contribution to a Sociology of Detachment." Revue Française de Sociologie (English) 53 (2):117-46.

. 2017. "Moving towards innovation through withdrawal: the neglect of destruction." In Critical Studies of Innovation: Alternative Approaches to the Pro-Innovation Bias, edited by Benoit Godin and Dominique Vinck, 97-114. Cheltenham: Edward Elgar Publishing.

Hagberg, Johan. 2016. "Agencing practices: a historical exploration of shopping bags." Consumption Markets \& Culture 19 (1):111-32.

Hawkins, Gay. 2011. "Packaging water: plastic bottles as market and public devices." Economy and Society 40 (4):534-52.

Hébert, Karen. 2014. "The matter of market devices: Economic transformation in a southwest Alaskan salmon fishery." Geoforum 53:21-30.

Hennion, Antoine. 1983. "Une sociologie de l'intermédiaire: le cas du directeur artistique de variétés." Sociologie du Travail 25 (4):435-53.

\section{- 2015. The Passion for Music: A Sociology of Mediation Farnham: Ashgate.}

Henry, Matthew. 2017. "Meat, metrics and market devices: Commensuration infrastructures and the assemblage of 'the schedule' in New Zealand's red meat sector." Journal of Rural Studies 52:100-9.

Huddart Kennedy, Emily, John R. Parkins, and Josée Johnston. 2018. "Food activists, consumer strategies, and the democratic imagination: Insights from eat-local movements." Journal of Consumer Culture 18 (1):149-68.

Ilbery, Brian, and Damian Maye. 2005. "Alternative (shorter) food supply chains and specialist livestock products in the Scottish - English borders." Environment and planning $A 37$ (5):823-44.

Jarosz, Lucy. 2008. "The city in the country: Growing alternative food networks in Metropolitan areas." Journal of Rural Studies 24 (3):231-44.

Karpik, Lucien. 1996. "Dispositifs de confiance et engagements crédibles." Sociologie du Travail 38 (4):527-50.

_ 2000. "Le Guide rouge Michelin." Sociologie du Travail 42 (3):369-89.

Kjellberg, Hans, Frank Azimont, and Emma Reid. 2015. "Market innovation processes: Balancing stability and change." Industrial Marketing Management 44 (1):4-12. 
Klein, Kendra. 2015. "Values-based food procurement in hospitals: the role of health care group purchasing organizations." Agriculture and Human Values 32 (4):635-48.

Kneafsey, Moya, Lewis Holloway, Laura Venn, Elizabeth Dowler, Rosie Cox, and Helena Tuomainen. 2008. Reconnecting consumers, producers and food: Exploring alternatives. Oxford: Berg Publishers.

Laforge, Julia M. L., Colin R. Anderson, and Stéphane M. McLachlan. 2017. "Governments, grassroots, and the struggle for local food systems: containing, coopting, contesting and collaborating." Agriculture and Human Values 34 (3):663-81.

Latour, Bruno. 2005. Reassembling the social : an introduction to actor-network-theory. Oxford: Oxford University Press.

Le Velly, Ronan. 2019. "Allowing for the projective dimension of agency in analysing alternative food networks." Sociologia Ruralis 59 (1):2-22.

Le Velly, Ronan, and Ivan Dufeu. 2016. "Alternative food networks as "market agencements": Exploring their multiple hybridities." Journal of Rural Studies 43:173-82.

Le Velly, Ronan, and Frédéric Goulet. 2015. "Revisiting the importance of detachment in the dynamics of competition." Journal of Cultural Economy 8 (6):689-704.

Le Velly, Ronan, and Marc Moraine. 2020. "Agencing an innovative territorial trade scheme between crop and livestock farming: the contributions of the sociology of market agencements to alternative agri-food network analysis." Agriculture and Human Values.

Leyshon, Andrew, Roger Lee, and Colin C Williams. 2003. Alternative economic spaces. London: Sage.

MacKenzie, Donald A, Fabian Muniesa, and Lucia Siu. 2007. Do economists make markets? On the performativity of economics. Princeton: Princeton University Press.

Mallard, Alexandre. 2012. "Developing uses, qualifying goods: on the construction of market exchange for Internet access services." Consumption Markets \& Culture 15 (2):191-211.

McArthur, Ellen. 2015. "Many-to-many exchange without money: why people share their resources." Consumption Markets \& Culture 18 (3):239-56.

Mellet, Kevin, and Thomas Beauvisage. 2019. "Cookie monsters. Anatomy of a digital market infrastructure." Consumption Markets \& Culture forthcoming.

Michel, Sophie, Florent Saucède, Catherine Pardo, and Hervé Fenneteau. 2019. "Business interaction and institutional work: When intermediaries make efforts to change their position." Industrial Marketing Management 80:266-79.

Moraes, Caroline, Isabelle Szmigin, and Marylyn Carrigan. 2010. "Living productionengaged alternatives: An examination of new consumption communities." Consumption Markets \& Culture 13 (3):273-98. 
Mundler, Patrick. 2013. "Le prix des paniers est-il un frein à l'ouverture sociale des AMAP ? Une analyse des prix dans sept AMAP de la Région Rhône-Alpes." Économie rurale (336):3-19.

Muniesa, Fabian, Yuval Millo, and Michel Callon. 2007. Market Devices. Oxford: Blackwell Publishers.

Onyas, Winfred Ikiring, Morven G. McEachern, and Annmarie Ryan. 2018. "Coconstructing sustainability: Agencing sustainable coffee farmers in Uganda." Journal of Rural Studies 61:12-21.

Ouma, Stefan. 2015. Assembling export markets. The making and unmaking of global food connections in West Africa. Oxford: Wiley.

Pellandini-Simányi, Léna, and Zsuzsanna Vargha. 2019. "Legal infrastructures: How laws matter in the organization of new markets." Organization Studies forthcoming.

Slater, Don. 2002. "From calculation to alienation: disentangling economic abstractions." Economy and Society 31 (2):234-49.

Thompson, Craig J., and Gokcen Coskuner-Balli. 2007. "Countervailing Market Responses to Corporate Co-optation and the Ideological Recruitment of Consumption Communities." Journal of Consumer Research 34 (2):135-52.

Trompette, Pascale. 2007. "Customer Channeling Arrangements in Market Organization: Competition Dynamics in the Funeral Business in France." Revue française de sociologie (English) 48 (5):3-33.

Wang, Chi-Mao. 2018. "Assembling lettuce export markets in East Asia: Agrarian warriors, climate change and kinship." Sociologia Ruralis 58 (4):909-27. 